\title{
SAÚDE, ESPIRITUALIDADE E O DEUS DE ESPINOSA
}

\section{HEALTH, SPIRITUALITY AND SPINOZA'S GOD.}

\section{SALUD, ESPIRITUALIDAD Y EL DIOS DE ESPINOSA}

\author{
Agnes Claudine Fontes De La Longuiniere ${ }^{1}$, Alba Benemérita Alves Vilela ${ }^{2}$, André Souza dos Santos ${ }^{3}$, Vital Ataíde da Silva ${ }^{4}$, Sérgio \\ Donha Yarid ${ }^{5}$
}

\section{RESUMO}

Objetivo: O objetivo desta reflexão teórica é analisar a aproximação da definição que se tem atualmente de Espiritualidade e a definição de Deus para o filósofo Espinosa. Método: Trata-se de uma reflexão teórica em que, seguindo o conceito de Deus, trazido por Espinosa em sua obra Ética, foi realizada uma aproximação deste conceito com a Espiritualidade e seus impactos para a saúde da população. Resultados: O conceito de espiritualidade vem se modificando ao longo da história, sendo, nos dias atuais, defendido como uma dimensão inerente ao ser que se manifesta na forma em que ele se relaciona consigo mesmo, com o outro e com a natureza. As questões relacionadas à dimensão espiritual e religiosa sempre fizeram parte dos questionamentos dos filósofos que, ao longo dos tempos, tentaram explicar a existência de Deus e de que modo a relação com o sagrado influenciava o modo de vida das pessoas. Espinosa se destaca, nesse cenário, ao trazer uma definição de Deus que se contrapõe à defendida pela teologia judaico-cristã de sua época. Ele traz uma concepção de Deus imanente, infinito e é causa, não transitiva, de todas as coisas. Assim, Deus é natureza e tudo o que existe está em Deus e Deus está em tudo. Conclusão: Sendo parte da substância infinita de Deus, somos compostos de atributos, como extensão (corpo) e pensamento (alma), sendo assim constituídos de corpo e alma que são inseparáveis, ambos são parte de uma mesma e única substância. Dessa forma, a vivência da espiritualidade pode afetar positivamente o corpo que, em consequência, influenciará a alma. A partir dessa aproximação mente e corpo, Espinosa demonstra a potência pensante da alma, que percebe a existência de seu corpo pela compreensão de suas afecções.

Descritores: Espiritualidade. Religião. Natureza. Filosofia.

\section{ABSTRACT}

Objective: The objective of this theoretical reflection is to analyze the approximation of the current definition of Spirituality and the definition of God according to the philosopher Spinoza. Methods: It is a theoretical reflection that, starting from the concept of God brought by Spinoza in his work Ethics, sought an approximation of this concept with Spirituality and its impacts on the health of the population. Results: The concept of spirituality has been changing since the twentieth century, and is now defended as an inherent dimension of the human being and manifests itself in the way humans connect to themselves, to others and to nature. Questions related to the spiritual and religious dimension have always been part of the questions of the philosophers who throughout history have tried to explain the existence of God and how the relationship with the sacred influenced people's lives. Spinoza stands out in this scenario by bringing a definition of God that contrasts with that defended by the JudeoChristian theology of his time. He puts forward a conception of God being immanent, infinite, and the non-transitive cause of all things. Thus, God is nature and everything that exists is in God and God is in everything. Conclusion: Being part of the infinite substance of God, we are composed of attributes such as extension (body) and thought (soul), and, thus, constituted of body and soul that are inseparable; both are part of one and the same substance. Thus, the experience of spirituality can positively affect the body and the latter will, consequently, influence the soul. From this approximation of mind and body, Spinoza demonstrates the rational power of the soul, which perceives the existence of its body by understanding its affections.

Descriptors: Spirituality; Religion; Nature; Philosophy.

\section{RESUMEN}

Objetivo: El objetivo de esta reflexión teórica es analizar la aproximación de la definición que se tiene actualmente de Espiritualidad y la definición de Dios para el filósofo Espinosa. Método: Se trata de una reflexión teórica en que, partiendo del concepto de Dios traído por Espinosa en su obra 'Ética', fue realizada una aproximación de este concepto con la Espiritualidad y sus impactos para la salud de la población. Resultados: La espiritualidad ha sido relacionada con el bienestar físico, la calidad de vida y ha sido considerada un factor de enfrentamiento de enfermedades. El concepto de espiritualidad ha estado sufriendo modificaciones desde el siglo XX, siendo actualmente defendida como una dimensión inherente al ser que se manifiesta en la forma en que este se relaciona consigo mismo, con el otro y con la naturaleza. Las cuestiones relacionadas a la dimensión espiritual y religiosa siempre fueron parte de los cuestionamientos de los filósofos que a lo largo de la historia intentaron explicar la existencia de Dios y de qué modo la relación con lo sagrado influenciaba el modo de vida de las personas. Espinosa se destaca en ese escenario al traer una definición de Dios que se contrapone a la defendida por la teología judaico-cristiana de su época. Trae una concepción de Dios inmanente, infinito y causa no transitiva de todas las cosas. Así, Dios es naturaleza y todo lo que existe está en Dios y Dios está en todo. Conclusión: Siendo parte de la substancia infinita de Dios, somos compuestos de atributos como extensión (cuerpo) y pensamiento (alma), siendo así constituidos de cuerpo y alma que son inseparables, ambas son parte de una misma y única substancia. De esta forma, la vivencia de la espiritualidad puede afectar positivamente al cuerpo y ese, consecuentemente, influenciará al alma. A partir de esta aproximación, mente y cuerpo, Espinosa demuestra la potencia pensante del alma, que percibe la existencia de su cuerpo por la comprensión de sus afecciones. Descriptores: Espiritualidad; Religión; Naturaleza; Filosofía.

1 Professora Assistente do Departamento de Saúde II da Universidade Estadual do Sudoeste da Bahia. Doutoranda do Programa de Pós-graduação em Enfermagem e Saúde da Universidade Estadual do Sudoeste da Bahia ${ }^{2}$ Professora Titular do Departamento de Saúde II da Universidade Estadual do Sudoeste da Bahia. ${ }^{3}$ Graduado em Filosofia. Professor Adjunto do Departamento de Ciências Humanas e Letras da Universidade Estadual do Sudoeste da Bahia. ${ }^{4}$ Graduado em Filosofia. Professor Assistente do Departamento de Ciências Humanas e Letras da Universidade Estadual do Sudoeste da Bahia. ${ }^{5}$ Cirurgião Dentista. Professor Adjunto do Departamento de Saúde I da Universidade Estadual do Sudoeste da Bahia. 


\section{INTRODUÇÃO}

A espiritualidade tem sido estudada em todo o mundo e seu reconhecimento, como fator que influencia a situação de saúde, bem-estar e qualidade de vida das pessoas, é tema de numerosas pesquisas e publicações científicas nos últimos anos.

A saúde é definida pela Organização Mundial da Saúde (OMS) como um bem-estar físico, psíquico, emocional e espiritual, o que exclui a ideia de que saúde é apenas a ausência de doença. Por muito tempo, a medicina valorizou os cuidados em saúde apenas do ponto de vista do corpo físico, dissociado da dimensão social, psíquica e espiritual. Mas, atualmente, tem-se direcionado ao reconhecimento de que o homem não é apenas corpo, matéria, mas que deve ser entendido, em suas múltiplas dimensões, e tratar de sua saúde inclui considerar a sua integralidade, inclusive, a sua espiritualidade.

Estudos recentes apontam que a dimensão espiritual do indivíduo tem grande impacto na prevenção de doenças, recuperação da saúde ${ }^{(1)}$, enfrentamento de enfermidades graves e resulta em impacto positivo na sobrevida das pessoas que sofrem desses males ${ }^{(2)}$. Esse reconhecimento, nas diferentes áreas da saúde, aumentou o número de estudos realizados no mundo inteiro e diversas são as evidências científicas que comprovam sua importância para a qualidade de vida e para o bem-estar físico e mental ${ }^{(3)}$.

A espiritualidade dos pacientes tem sido referida como importante fator a ser estimulado, durante a assistência à saúde, pois o ser é multidimensional e sua dimensão espiritual deve ser considerada, em seu plano terapêutico, visto que pode influenciar na maneira como o indivíduo enfrenta o processo de adoecimento, tratamento e recuperação.

A ligação entre medicina e religião faz-se, desde os tempos mais antigos, quando o surgimento das doenças e a sua cura eram atribuídos a divindades ou seres espirituais como forma de castigo ou benefício para os humanos. A partir do Renascimento, porém, houve uma separação entre a ciência e a religião que se manteve até o século $X X^{(4)}$.

Até o século $\mathrm{XIX}$, religião e espiritualidade foram consideradas como sinônimos, mas, a partir dessa época, estabeleceu-se gradualmente uma distinção entre elas. Dessa maneira, a religião passou a ser entendida como uma prática institucionalizada de um sistema de crenças, rituais e símbolos compartilhados por uma comunidade. Por outro lado, a espiritualidade foi entendida como uma busca pessoal por significado e sentido no existir e sua relação com o sagrado, podendo estar ligada ou não a uma religião ${ }^{(5)}$.

Contudo a comunidade científica ainda não chegou a um consenso sobre o conceito de espiritualidade. Para muitos, espiritualidade e religião costumam ser consideradas como sinônimos e, em alguns estudos científicos, essa diferenciação não ocorre de maneira clara. Configura-se um desafio encontrar uma definição para a espiritualidade, pois nenhuma das acepções existentes consegue abranger todo o seu significado. Entretanto pode-se dizer que ela é formada por diferentes conceitos interligados ${ }^{(6)}$.

Estudos que buscam refletir sobre questões, que vão além do ser biológico, que reconhecem o indivíduo como um ser que possui múltiplas dimensões, que estão interligadas e impactam neste ser são importantes, sobretudo, quando se busca conversar com reflexões de estudiosos e outras ciências como a filosofia. Assim, reflexões acerca da dualidade corpo e mente e da influência da dimensão espiritual, no corpo físico, podem ampliar a concepção de saúde e o modo como a promoção, prevenção e tratamento em saúde são percebidos.

As questões ligadas à espiritualidade, à religião e ao Ser sempre foram discussões presentes na história da humanidade. Desde tempos remotos, filósofos se interessaram em explicar a concepção de Deus e o que representava para as pessoas e como interferia em suas vidas. Assim, esses conceitos perpassaram o entendimento comum, a cada época e, em alguns momentos, sua definição foi bastante diferente da compreensão teológica que se tinha de Deus. Nesse sentido, Espinosa destacou-se, ao trazer uma concepção diferente de Deus daquela que existia até o século XVII que era a de um Deus transcendente, separado do homem, sentado em um trono, para julgar as pessoas e puni-las pelos seus atos.

Desta forma, o objetivo desta reflexão teórica é analisar a aproximação da definição que se tem atualmente de Espiritualidade e a definição de Deus do filósofo Espinosa.

\section{MÉTODO}


A definição de Deus defendida por Espinosa difere da conceituação judaico-cristã que predominava em sua época. Para ele, Deus é uma potência infinita de existir e tudo na natureza deve ser pensado a partir da sua existência. Portanto "Deus é causa imanente, e não transitiva, de todas as coisas" ${ }^{\prime(7)}$. Deus é natureza, não havendo, nessa ótica, uma separação entre toda coisa existente e um Deus transcendente, que é separado, superior e criador de toda a criatura, que observa, julga e decide todas as coisas, como concebido pela religião judaico-cristã.

Em seu livro Ética, publicado postumamente, em 1677, Espinosa descreve suas ideias sobre questões mais fundamentais da metafísica. Em sua Parte I, o livro discorre sobre Deus, sua definição, axiomas e diversas proposições quanto à sua definição. O livro traz, ainda, na segunda parte, informações sobre a origem e natureza da mente, origem e natureza dos afetos (terceira parte) e sobre a servidão Humana ou sobre a força dos afetos (quarta parte).

A concepção de Deus entendida e defendida por Espinosa é um conceito que muito se assemelha à concepção de espiritualidade que se tem discutido, sendo a mais aceita atualmente pela comunidade científica. Assim sendo, este estudo é uma reflexão teórica em que foi utilizada a parte I do livro a Ética, de Baruch de Espinosa, para compreender a sua definição de Deus e, a partir daí, foi realizada uma análise de sua aproximação com $o$ conceito de Espiritualidade, trazido pelos estudiosos da atualidade, relacionando ainda com a questão da saúde.

\section{RESULTADOS E DISCUSSÃO}

Para Espinosa, Deus e a natureza são a mesma coisa, a natureza está contida em Deus, sendo parte dele, e é preciso conhecer a natureza, se quisermos conhecer a Deus, pois tudo advém de Deus e tudo está em Deus. Segundo Espinosa, "Por causa de si entendo aquilo cuja essência envolve a existência" ${ }^{(7)}$. Portanto Deus é substância infinita e, assim sendo, nada pode existir fora dele. E essa substância existe por si só, não dependendo de mais nada para existir, existe apenas pela necessidade de existir e não é determinada por nada, além de conter atributos e modos que contribuem com o aspecto de substância. E nós somos todos modos da substância divina.
Deus, sendo natureza, tudo que existe é parte imanente de Deus, "Tudo o que existe, existe em Deus e, sem Deus, nada pode existir nem ser concebido" ${ }^{\prime 7)}$. Assim, parte da potência de Deus se manifesta em nós, e toda a ação existente na natureza é ação exclusivamente de Deus pelas leis da natureza, sem ser coagido por ninguém, tudo decorre da essência de Deus ${ }^{(7)}$.

Sendo parte da causa divina, vivendo de acordo com a potência em nós, agimos conforme as leis da natureza contida em Deus. Esse pensamento nos faz acreditar que não há erros nos acontecimentos, não há bem nem mal, pecado nem imperfeição, pois tudo que existe, existe a partir da necessidade de existir de Deus, sendo tudo isso duas faces de um mesmo Ser, dado que tudo decorre da sua essência e tudo que existe é parte dessa substância.

"Por Deus entendo o ente absolutamente infinito, isto é, uma substância que consta de infinitos atributos, cada um dos quais exprime uma essência eterna e infinita”(7). A substância é aquilo que não necessita de nada além de si para existir, cujo conceito não necessita de outro conceito para existir e que exprime sua essência em diferentes atributos. Por atributo entende-se aqueles elementos que o intelecto percebe como parte que constitui a essência da substância - e esses são infinitos e concebidos em si mesmos (pensamento e extensão). Além dos atributos e da substância, também os modos são as afecções da substância, ou seja, o que existe, em outra coisa, é por meio da qual também é concebida. Os modos só existem, porque existe a substância e seus atributos, sendo o modo procedente e determinado pelos atributos ${ }^{(7)}$.

Em Espinosa, Deus representa a ideia de totalidade como única substância existente, à medida que ele afirma que Deus é aquilo que existe por si só e que tudo o que existe em Deus é parte essencial de Deus, assim, tudo é Deus e Deus é tudo, "Deus é natureza". Deus é o ser humano, os animais, as plantas, o céu e a lua. Deus é tudo que existe e tudo existe como parte imanente de Deus, a natureza não está separada de Deus, mas intimamente ligada, formando uma mesma coisa. Tudo que existe é um produto de Deus, uma expressão necessária da potência de Deus e não uma criação do divino. Essa ideia panteísta (tudo é Deus ou manifestação necessária de Deus), defendida por Espinosa, expande Deus a todas as coisas e concebe Deus intimamente presente em tudo. 
A posição defendida por Espinosa rompeu com qualquer interpretação de Deus defendida pelas religiões da sua época. $O$ conceito de Deus, para as principais religiões ocidentais, é a de uma pessoa imaterial, um ser transcendente à natureza, que se encontra separado do universo, sendo toda a natureza sua criação, a qual ele controla de acordo com a sua própria vontade e há uma dominação do criador sobre a criatura. 0 Deus defendido pelas religiões é um Deus antropomórfico, uma imitação do homem, inclusive, com atributos humanos, dotado de personalidade ${ }^{(8)}$.

Ao romper com esta concepção de Deus das principais religiões, Espinoza traz uma relevância ética para o conceito de bem-viver diante das coisas do cotidiano. Ao concluir parte do seu livro, a Ética, ele aponta quatro utilidades dessa concepção. Quando nos permitimos agir, de acordo com a necessidade de Deus, a partir do amor e da piedade, teremos o espírito tranquilo e encontraremos a nossa suprema felicidade e liberdade, visto que somos parte da natureza divina e nossas ações devem ter sua recompensa em si mesmas.

Para ele, essa doutrina também é eticamente útil, para nos orientar diante das coisas que não estão, em nosso poder, não são da nossa natureza, entendendo que devemos aceitar e esperar com bons ânimos, confiando que tudo procede de Deus e da sua necessidade de existir. Facilita ainda a vida social à medida que ensina a não odiar, desprezar, invejar ou conflitar com o outro, aceitando os acontecimentos e ajudando sempre o próximo sob a guia da razão. E, finalmente, Espinosa atribui à essa doutrina a utilidade de facilitar o entendimento de como a sociedade deve ser governada, não para que sirva, mas para que se realize livremente o que é melhor.

Espinosa traz esta dimensão de Deus, sendo explicada filosoficamente como verdade e remete o conceito de Deus das religiões à imaginação, à fantasia, com o intuito de obter obediência. Assim, o objetivo da religião seria, para ele, levar o povo a obedecer a Deus, honrálo e servi-lo ${ }^{(9)}$. E essa concepção é ainda muito próxima da que temos atualmente sobre a religião.

A religião é, na atualidade, considerada um sistema de crenças, práticas, rituais que facilitam o acesso ao Sagrado, ligada a uma instituição, com características comportamentais, sociais e doutrinárias semelhantes e específicas que são compartilhadas por um grupo, mas praticadas individualmente ${ }^{(4)}$. Pode ser entendida ainda como a extensão na qual o indivíduo se envolve com um sistema de crenças e práticas compartilhadas por uma comunidade, destinadas à aproximação com o sagrado ou ao transcendente, que envolve uma doutrina, regras de conduta, rituais organizados e sempre ligados a uma instituição ${ }^{(10)}$.

De outra forma, a concepção de Deus, entendida e defendida por Espinosa, é um conceito que muito se assemelha à concepção de espiritualidade que se tem discutido, sendo a mais aceita atualmente pela comunidade científica.

A espiritualidade é defendida como dimensão essencial e inerente ao ser humano, estando presente no cotidiano e na intimidade de todas as pessoas, dos ateus aos religiosos, de forma íntima e constante. A espiritualidade é a essência humana pela busca de significados e o propósito de vida, incluindo a relação consigo mesmo, com o outro, com a natureza e com o sagrado, permitindo alcançar uma intimidade com algo maior e uma compreensão do universo além de ser parte da dimensão existencial do $\operatorname{ser}^{(5)}$.

Ter espiritualidade é estar em conexão consigo mesmo, é um senso de responsabilidade com o outro e com a natureza, é um viver ético, respeitando tudo o que existe, não necessitando da religião para existir, pois é uma característica íntima e inerente ao ser. É algo que está além da religião e não é compreendida como o seu sinônimo.

A espiritualidade está relacionada a valores íntimos de harmonia e completude interior, conexão com os outros, estimulando o interesse pelos outros e por si, uma unidade com a vida e com a natureza, com o universo. Pode ser entendida ainda como uma busca pessoal, para compreender o sentido da vida, a relação com o sagrado $^{(11)}$.

Assim, a espiritualidade é muito mais do que a manifestação religiosa. Ela é um instrumento que torna o homem cada vez mais humano, criando laços de fraternidade e fortalecendo a ética, na relação que o homem desenvolve com tudo o que existe, à medida que ele busca dentro de si uma presença divina, dando-lhe condições para ser ético, humano, fraterno, à proporção que se reconhece como parte inseparável de tudo que existe. 
O pensamento de Espinosa reflete exatamente o modo como o homem olha para o mundo, vendo Deus desde o seu interior, ao contrário da teologia que o enxerga de dentro para fora, como um ser transcendente. Portanto considera que tudo o que há forma uma unidade inseparável com Deus, tudo está em Deus e Deus está em tudo ${ }^{(12)}$.

\section{CONSIDERAÇÕES FINAIS}

Muitos aspectos da espiritualidade estão contidos no significado de Deus em Espinosa, sobretudo, no que diz respeito à relação ética do homem consigo mesmo, com o outro e com a natureza, reconhecendo-se parte integrante do universo e reconhecendo que suas ações têm impacto no todo e que o todo interfere na parte em que o homem está contido.

Dessa forma, diversos estudos científicos têm comprovado que trabalhar a espiritualidade, reconhecendo-a como uma dimensão que não pode ser dissociada do ser, reconecta-nos com a nossa essência e, consequentemente, traz-nos bem-estar físico e mental, melhorando significativamente nossa qualidade de vida. Talvez isso se justifique exatamente por ser essa dimensão a possibilidade de se reconhecer como um todo, agindo com compaixão e consciência, fazendo o bem e tendo nessas ações a felicidade suprema em si mesma e, em nossas bemaventuranças, visto que agimos, de acordo com a nossa natureza, que é parte da natureza divina e da sua necessidade de existir.

Sendo parte da substância infinita de Deus, somos compostos de atributos como extensão (corpo) e pensamento (alma), sendo assim constituídos de corpo e alma que são inseparáveis, ambos são parte de uma mesma e única substância. Logo está na natureza da mente ter uma conexão com o corpo e vice-versa, e qualquer impacto em um será também um impacto no outro. Dessa forma, a vivência da espiritualidade pode afetar positivamente 0 corpo que, em consequência, influenciará a alma. A partir dessa aproximação mente e corpo, Espinosa demonstra a potência pensante da alma, que percebe a existência de seu corpo pela compreensão de suas afecções ${ }^{(13)}$.

Isso considerado, podemos reconhecer que a potência de agir do nosso corpo pode ser estimulada e aumentada quando a mente afeta $o$ corpo de maneira positiva. Da mesma forma, quando a mente imagina coisas que diminuem a potência de agir do corpo, tanto a potência da mente quanto a do corpo diminui. A maneira como corpo e mente estão ligados e se afetam mutuamente pode interferir na condição de saúde das pessoas.

Esse reconhecimento de que corpo e mente não devem ser tratados separadamente, pois um afeta positiva ou negativamente o outro, tem feito com que a espiritualidade do indivíduo seja incluída nos currículos de profissionais da saúde. No Brasil, essa realidade ainda tem sido incipiente, mas, nos Estados Unidos da América, aproximadamente, $90 \%$ das escolas médicas abordam esse tema durante a graduação ${ }^{(14)}$.

Quando vivenciamos a nossa espiritualidade, agimos como parte de Deus, que é imanente à natureza e somos levados a agir de maneira ética, universal, preservando a vida como um todo. Assim, nosso espírito produzirá melhor a natureza já que dela é essência, ordem e união.

\section{REFERÊNCIAS}

1- Nsamenang SA, Hirsch JK, Topciu R, Goodman $A D$, Duberstein PR. The interrelations between spiritual well-being, pain interference and depressive symptoms in patients with multiple sclerosis. J Behav Med. 2016;39(2): 355-63. DOI: 10.1007/s10865-016-9712-3

2- Ironson G, Kremer H, Lucette A. Relationship between spiritual coping and survival in patients with HIV. J Gen Intern Med. 2016;31(9):1068-76. DOI: 10.1007/s11606-016-3668-4

3- Koenig HG. Espiritualidade no cuidado com o paciente: Por quê, como, quando e o quê? 2a ed. São Paulo: FE Editora Jornalista; 2012.

4- Koenig HG, Mccullough $M$, Larson DB. Handbook of religion and health: A century of research reviewed. New York: Oxford University Press; 2001.

5- King MB, koenig HG. Conceptualising spirituality for medical research and health service provision. BMC Health Serv Res. 2009;9(1):116. DOI: 10.1186/1472-6963-9-116

6- Dezorzi LW, Crossetti MGO. A espiritualidade no cuidado de si para profissionais de enfermagem em terapia intensiva. Rev Latino-Am Enfermagem 2008; 16(2):212-7. DOI: 10.1590/S0104-11692008000200007

7- Spinoza BB. Ética: Demonstrada à maneira dos geômetras. 3a ed. Belo Horizonte: Autêntica; 2010.

8- Almeida PJ, Albertuni CA. A concepção imanente de Deus em Espinosa. In: Anais do 8o Seminário de Pesquisa em Ciências 
Humanas;2010, Londrina. Londrina: SEPECH; 2010. p. 1631-42.

9- Reale G. História da Filosofia: Do Humanismo a Kant. 8a ed. São Paulo: Paulus; 2007.

10- Kimura M, Oliveira AL, Mishima LS, Underwood LG. Adaptação cultural e validação da Underwood's Daily Spiritual Experience Scaleversão brasileira. Rev Esc Enferm USP 2012;46(nesp):99-106. DOI: 10.1590/S0080$\underline{62342012000700015}$

11- Guerrero GP, Zago MMF, Sawada NO, Pinto $\mathrm{MH}$. Relação entre espiritualidade e câncer: Perspectiva do paciente. Rev Bras Enferm. 2011;64(1):53-9. DOI: 10.1590/5003471672011000100008

12- Ponczek RL. Deus, ou seja, a natureza: Spinoza e os novos paradigmas da física. Salvador: EDUFBA; 2009.

13- Nascimento LPGX. Uma análise da ideologia nazista a partir da ética de Espinosa. Revista Filosofia Capital. 2016 [citado em 15 ago 2018]; 11(nesp):89-98. Disponível em: http://www.filosofiacapital.org/ojs-

2.1.1/index.php/filosofiacapital/article/view/335 14- Lucchetti G, Lucchetti ALG, Espinha DCM, Oliveira LR, Leite JR, Koenig HG. Spirituality and health in the curricula of medical schools in Brazil. BMC Med Educ. 2012;12(1):78. DOI: $\underline{10.1186 / 1472-6920-12-78}$

Nota: Os autores declaram não haver conflito de interesses.

Recebido em: 04/12/2018

Aprovado em: 08/10/2019

Endereço de correspondência:

Agnes Claudine Fontes De La Longuiniere

Universidade Estadual do Sudoeste da Bahia. Rua José Moreira Sobrinho S/N. Jequiezinho.

CEP: 45205-490 - Jequié/BA - Brasil

E-mail: agnesfontes@uesb.edu.br 